Ana María Cristi C.

\title{
La producción de subjetividades marginales en Fuerzas especiales de Diamela Eltit: la emergencia de un enfoque guattariano
}

\section{The Production of Marginal Subjectivities in Fuerzas especiales by Diamela Eltit: the Emergence of a Guattarian Approach}

\begin{abstract}
Resumen
El presente artículo propone analizar la producción de subjetividades marginales en la obra Fuerzas especiales de Diamela Eltit. Para ello se examinará en la narración, desde el planteamiento teórico desarrollado por Félix Guattari, la conformación material que se gesta entre sujeto, espacio y tecnología. La propuesta de lectura es concebir Fuerzas especiales como una performance escritural, en donde la palabra-acción busca romper con la homogeneidad estética y conceptual de la literatura canónica para, desde allí, abrir un campo de experimentación que conjuga nuevas corporalidades, espacialidades y sonoridades desde el margen (social y estético).
\end{abstract}

Palabras claves

Diamela Eltit, Fuerzas especiales, subjetividades, Félix Guattari, performance, CMI

\begin{abstract}
This article proposes to analyze the production of marginal subjectivities in Diamela Eltit's Fuerzas especiales. To this end, from the theoretical approach of Félix Guattari, the material conformation that takes place between subject, space and technology will be examined. The reading proposal is to conceive Fuerzas especiales as a scriptural performance, where the word-action seeks to break with the aesthetical and conceptual homogeneity that governed canonical literature, and, from there, to open a field of experimentation that combines new corporalities, spatialities and sonorities from the margin (social and aesthetic).
\end{abstract}




\section{Introducción}

"Edificios habitables en diámetros precisos. Eso fue lo que obsequiaron" Diamela Eltit, Lumpérica.

La escritura como forma de resistencia política y denuncia social es consustancial a la propuesta literaria de Diamela Eltit. En su caso, el interés por adentrarse en las múltiples facetas que subyacen al "sujeto desagregado" que habita el territorio nacional, implica situar su narrativa dentro de un contexto historiográfico de resistencia y contracultura que emerge durante el periodo de la dictadura militar (1973-1989) y posdictadura en Chile. En este aspecto, la escritora se interesa por hacer visible y ampliar hacia nuevas posibilidades de interpretación la crisis de la identidad nacional escrita "desde arriba" o manipulada por las elites del país. De esta manera la obra de Diamela Eltit se caracteriza por la puesta en obra de una escritura desbordante que propone nuevas directrices para la literatura a partir de la constante transgresión del lenguaje y la fragmentación de los géneros literarios, apostando, de este modo, por una reformulación política-estética en la literatura.

En el año 2013 aparece la décima novela de Diamela Eltit: Fuerzas especiales. Libro en el que se retoma la problemática de la segregación social, la compartimentación unilateral de la ciudad, los cercos de la periferia urbana y la cotidianidad de los cuerpos relacionantes que allí se manifiestan mediante múltiples y variadas conexiones. En este contexto, Fuerzas especiales es un pequeño universo sitiado y en alerta compuesto por bloques habitacionales, depredadores tecnológicos, enfrentamientos de pandillas y hostigamiento policial. Insistiendo en los lugares narrativos que caracterizan la obra de Diamela Eltit, la escritora logra resituar la emergencia de una problemática social sumamente contingente, en la cual se cuestiona las relaciones de poder que constituyen la dinámica de un contexto urbano dual y asimétrico. Así pues, Fuerzas especiales es un acto de violencia. Un desborde de violencia urbana en todos sus registros, violencia que se ejecuta en una 
escritura desconcertante que remece, abusa y flagela cada página que constituye la novela.

En este aspecto, cabe destacar que la visión crítica de Diamela Eltit sobre la configuración de sujetos y subjetividades ha sido un importante foco de interés para variados críticos que, a través de distintas perspectivas, han abordado el problema. No obstante, respecto a Fuerzas especiales no ha existido un análisis exhaustivo en torno a dicha temática. Usualmente la novela ha sido leída en consideración a otras temáticas como el cuerpo o la ciudad. En este sentido, destacan algunos estudios recientes como el de Patricia Espinosa (2018) quien analiza la destrucción del sujeto popular en la novela y la relación que se gesta entre la hiperrealidad virtual y la utopía de cambio. Una perspectiva similar desarrolla Daniela Pinto (2018) quien examina la alegoría de la mujer-bloque y la construcción alegórica de subjetividades, cuya conformación se desarrolla mediante la producción económica y la cosificación del cuerpo. En esa misma línea Ethel Barja (2018) centra su análisis en la relación entre los cuerpos heridos y la escritura, siendo la experiencia intersubjetiva de la vulnerabilidad la que sustenta una escritura de la corporalidad. Algo que Luis Valenzuela Prado (2018) examina desde la noción de retórica visual y letra en tránsito, una performance que acontece, según el autor, desde la premisa de la conexión entre dispositivo, palabra y política. Perspectiva que, en cierto modo, se relaciona con el estudio de Laura Scarabelli (2018) quien da cuenta de las patologías de la contemporaneidad tras los efectos de la globalización ampliamente desarrollados en la novela de Eltit.

Anteriormente, Sandra Navarrete (2017), analiza la tríada espacio, sujeto marginal y miedo con la finalidad de evidenciar aquellos "miedos marginales" que conforman al sujeto y son producidos por la represión armada y la vulnerabilidad del espacio precario. Y estos miedos, al ser provenir de la periferia, tendrán como marcos la invisibilidad política y el olvido o falta de verdadera atención. De modo semejante, Francisca Arenas (2017) se aproxima en la obra a la relación que se gesta entre subjetividades y significación urbana, al sostener que la ciudad se presenta como un espacio inscrito y escrito mediante las experiencias del sujeto. 
Mientras que, por otra parte, Paola Lizana (2017) analiza la escritura de Fuerzas espaciales en su faceta marginal y rupturista, comprendiendo cómo sus desbordes permiten hacer visibles al sujeto anónimo, marginal y desterritorializado.

En vistas de lo anterior, el presente artículo analizará este pequeño universo socioespacial de Fuerzas especiales en vistas de escenificar la lucidez con que la escritora logra visibilizar los diversos regímenes que producen y regulan gran parte de la sociabilidad contemporánea. Dichos regímenes se presentan desde distintos ejes que en su conjunto logran alienar y producir cuerpos y subjetividades. Esta situación es localizada por Diamela Eltit en la periferia urbana con la finalidad de experimentar la rapidez y la turbulencia con que la era mediática-digital logra modificar subjetividades de acuerdo con los mandamientos constantemente actualizados del capitalismo que, en su conjunto, logran sujetar transversalmente a gran parte de la existencia humana. Por consiguiente, interesa mostrar cómo la producción de subjetividades marginales se construye fuera del sujeto en tanto el territorio periférico, la represión policial y las tecnologías digitales tiene como punto de convergencia la proyección del capitalismo avanzado. En esta línea, también interesa dar cuenta de la intensión propositiva de la novela mostrando, desde una perspectiva guattariana, cómo es posible reapropiarse de las tecnologías para devenir en una resistencia política-digital que posibilite la autopoiesis del sujeto marginal.

\section{La performance escritural de Diamela Eltit: una ruptura de discursos}

Visibilizar de entrada en la obra literaria de Diamela Eltit un espacio textual de subversión resulta oportuno si se pretende examinar aquellos componentes que permiten situar su narrativa dentro de las prácticas descentralizantes propias del arte y la literatura contemporánea. Esto, debido a que la particular composición narrativa que caracteriza el trabajo de la escritora se sustenta, entre otros factores, en la utilización de un lenguaje plástico que permite la elaboración constante de 
CATEDRAL TomAdA: Revista de crítica literaria latinoamericana / Journal of Latin American Literary Criticism

La producción de subjetividades marginales en Fuerzas especiales de Diamela Eltit: la emergencia de un enfoque guattariano

giros e innovaciones conceptuales mediante el uso de una marcada heteroglosia "multidiscursiva y multigenerica" (Prado 140). En efecto, su escritura trastoca la linealidad discursiva del texto literario mediante torsiones, fragmentaciones y montajes lingüísticos que permiten el advenimiento permanente de nuevas producciones de sentido.

La propuesta estético-literaria rupturista de Diamela Eltit se interesa por inscribir en su obra una poética de lo abyecto, en donde el lenguaje intenta, a través de su desfiguración, simular dentro de los parámetros de la ficción un espacio virtual que colinda con los bordes de la marginalidad social. En efecto, tras "el quiebre de la sintaxis [...] cuestiona la hilada organización del discurso e incursiona en zonas del lenguaje que descubren identidades y experiencias humanas límite que niegan la unicidad" (Lértora 12). Dicho cuestionamiento apunta a inscribir en el texto y desde el texto la configuración de la violencia urbana, el miedo a la opresión armada por parte del Estado y la resistencia política-vital de los sujetos desagregados de la sociedad. Con este propósito, Diamela Eltit elabora en Fuerzas especiales un lenguaje estratégico, cuyas proyecciones se divisan en la conformación de una narración rápida, abrupta, tensa y locuaz. Dicha narración se nutre del uso constante de la repetición, el ensamblaje de conceptos, la desfiguración lingüística (en tanto reproduce la oralidad del entorno) y la atemporalidad narrativa. El lenguaje, en este aspecto, se distingue como un soporte flexible que permite elaborar en el texto nuevas formas de significación, las cuales apelan a la experiencia límite y exhortan a la imaginación. Así se observa, por ejemplo, en las primeras páginas de la obra:

Pero la guatona es la guatona y me asusta y me da miedo y me provoca un terror parcial pues mi mamá, mi hermana y yo nos parecemos demasiado a la guatona, pero nosotras ganamos más. Yo gano más. Había tres mil pistolas Bruni 8mm. Gano más ahora que mi mamá está enferma y mi hermana también. Pero mi papá no, el no. (14) 
La palabra disruptiva que sustenta el movimiento errático/violento en que se configura la escritura de Diamela Eltit se presenta en Fuerzas especiales mediante la estructuración de una prosa no orgánica que proyecta, en su desorganización, una constante indiscernibilidad de las formas. En este registro, se hace patente la experiencia límite del lenguaje en la imbricación de diversos enunciados que aluden a la presencia de armamento militar, que se interponen (e intercalan) a lo largo de la narración. Enunciados tales como: "Había quince mil quinientos rifles Taurus M62" (18), "Había tres mil Murata 8mm” (42) o "Había mil misiles Pantsir-S” (104) logran desarmar la estructura regular de la narración (o la linealidad secuencial según la concordancia espacio-tiempo) para desmontar, mediante una práctica textual rupturista, la visión sintáctica y armónica de la literatura. En otras palabras, "la exuberancia y la fragmentación de su escritura pone en tela de juicio toda posibilidad misma de "catalogación" de las categorías de lo literario, quebrando fronteras y difuminando modelos y formas” (Scarabelli 974). Desde esta perspectiva, la palabra y su experiencia límite se conjuga en el texto apostando hacia el quiebre de la unidad de sentido, para proyectarse en nuevas formas de nombrar que apelan a la imaginación. Imaginación que, por lo demás, supera la propia textualidad de la obra al situarse como la acción que permite ficcionar "lo otro".

Resulta oportuno, entonces, considerar que "en la escritura de Eltit, el texto adquiere la doble dimensión de espacio descentralizador y descentralizante de políticas socio-literarias y culturales" (Olea 166). El texto se concibe como descentralizador, al configurarse mediante una escritura que reflexiona $y$ deconstruye al sistema literario (transgrediendo sus reglas y especificidades) ${ }^{1}$, y, al

\footnotetext{
${ }^{1}$ Es interesante relacionar esta perspectiva con las propias palabras de la escritora al referirse a su interés por las estéticas menos consensuadas. Estéticas que permiten posicionarse políticamente desde la producción textual misma. En sus palabras: “A mí me interesan las estéticas y, en ese sentido yo creo que la estética también tiene un filo político. Tú puedes tener unas estéticas más centristas, por decirlo de alguna manera, y puedes tener unas estéticas más desprogramadas de los consensos. A mí me han interesado esas estéticas menos consensuadas y ahí sí hay un compromiso político, pero no en el sentido de tener que escribir desde una posición determinada, sino que se trata más bien desde la estética que produces, ver el texto a qué estética te está afilando. Eso es una posición política" (Solorza 80).
} 
CATEDRAL Tomada: Revista de crítica literaria latinoamericana / Journal of Latin American Literary Criticism

La producción de subjetividades marginales en Fuerzas especiales de Diamela Eltit: la emergencia de un enfoque guattariano

mismo tiempo, se concibe como descentralizante al posicionarse (desde el margen) en una lucha por el poder interpretativo, en donde el lenguaje crea y pone de manifiesto espacios y subjetividades que permanecen en el anonimato del discurso oficial.

Hechas las observaciones anteriores, es posible comprender que la temática border que trabaja Diamela Eltit tanto en Fuerzas especiales como en el resto de su obra se caracteriza por configurarse desde una posición crítica, en donde la escritura se ejerce como una acción política manifiesta a través del ejercicio de la palabra dilatoria, ambigua y disidente. Dicha palabra-acción permite comprender la escritura de Eltit como una constante performance que utiliza el lenguaje en toda su expresión para re-escribir sujetos, cuerpos y espacios invisibilizados en el aparente orden social, estable y homogéneo. Este punto ha sido abordado por Nelly Richard en su prólogo a Lumpérica al indicar que:

Eltit fue modelando un trayecto de escrituras móviles que cambian de soporte [...] para experimentar roces desconocidos entre diversas y dispersas trazas de inscripción, materialidades significantes, voluntades de forma, aconteceres privados, modelajes estéticos y rupturas políticoculturales. En los bordes híbridos que median entre literatura y performance, entre acción de arte y registro video, entre intervención urbana y borrador cinematográfico, la escritora incorporó a su novela los excedentes gestuales y rituales de un trabajo cruzado que se volvió experto en entrar y salir de las categorías. (8)

En este registro, la relación entre literatura y performance que Nelly Richard observa en la composición de Lumpérica se sustenta en la ejecución de una escritura actuante (en tanto desborde y movimiento) que cuestiona las univocidades para proporcionar nuevas experiencias de significado. Esto también puede advertirse en Fuerzas especiales, en donde la palabra entra en juego mostrándose 
en toda su amplitud discursiva y aprehendiendo la textualidad corporal de aquellos cuerpos inscritos por los márgenes sociales.

En este contexto, resulta menester traer a colación el cuestionamiento de Paul B. Preciado acerca del éxito hermenéutico que ha tenido el concepto de performance en los distintos campos artísticos y sociales. Según Preciado, "sería necesario establecer una genealogía de la noción misma de performance que nos permita explicar la ruptura que este concepto opera en los discursos, las prácticas políticas y las instituciones artísticas" (21). Ruptura que, evidentemente, se posiciona como el eje que vincula la escritura de Eltit con este campo de experimentación cuyo sostén radica en la palabra-acción. En este sentido, performance y escritura se vinculan en lo que Erika Fisher-Lichte llama "el potencial transformador del arte" (26), donde la estética juega un rol primordial al generar (mediante la ruptura) nuevas formas de corporalidad, espacialidad y sonoridad.

En efecto, la performance escritural de Fuerzas especiales permite rebasar las fronteras de la palabra escrita para "hacer hablar" a los sujetos radicados en el margen. Esta acción en la escritura permite encarnar la experiencia violenta de la marginalidad, haciendo propia "la violencia con que su escritura tuerce y retuerce la mímesis cotidiana" (Hozven 311). La palabra-acción de Fuerzas especiales habita la vivencia y la precariedad de los espacios periféricos estableciendo una "comunicación estética con el público en la plenitud de la carne y el hueso" (Salcido 75), comunicación que se alcanza mediante la refracción de la realidad (y no su mera reproducción), en donde el lenguaje elabora múltiples capas de ensamblaje discursivo, los cuales logran configurar, a través del cuestionamiento epistemológico, nuevas subjetividades y nuevas formas no tradicionales de resistencia política. 
CATEDRAL Tomada: Revista de crítica literaria latinoamericana / Journal of Latin American Literary Criticism

La producción de subjetividades marginales en Fuerzas especiales de Diamela Eltit: la emergencia de un enfoque guattariano

\section{Sujeto bloque, cuerpos bloque, realidad bloque...}

Tomando en cuenta las observaciones anteriores, resulta necesario examinar cómo desde una perspectiva crítica la performance escritural de Fuerzas especiales logra hacer visible y cuestionar la producción material de las subjetividades marginales. Para ello, es importante insistir una vez más en la apuesta epistemológica de la literatura de Diamela Eltit, a saber, posicionar al sujeto como forma y no como sustancia, es decir, descentrar al sujeto unívoco para hacer aparecer, en el propio texto, las existencias de múltiples subjetividades. El sujeto aparece como una forma nunca idéntica a sí misma, nunca estática, sino más bien, en una permanente construcción. Sin embargo, aquella construcción nunca es totalmente libre, pues, en tanto proceso, se halla en constante relación con las prácticas culturales y contextuales en que el sujeto de desarrolla. Así lo explica Michel Foucault:

[El sujeto] es una forma, y esta forma no es ni ante todo ni siempre idéntica a sí misma [...] en cada caso, se juegan, se establecen respecto a uno mismo formas de relaciones diferentes [...] el sujeto se constituye de una forma activa, a través de las prácticas de sí, estas prácticas no son sin embargo algo que se invente el individuo mismo. Constituyen esquemas que él encuentra en su cultura y que le son propuestos, sugeridos, impuestos por su cultura, su sociedad y su grupo social. (403-404)

Según lo citado, se comprende que el sujeto se caracteriza por no ser nunca idéntico así mismo, por ser una construcción que se lleva a cabo a partir de factores externos, desde su afuera, ya que si bien le circunscriben y relacionan a una esfera determinada, lo hacen sólo de manera relativa. Al mismo tiempo, se comprende que concebir al sujeto en su génesis como un ser fragmentario, variable y múltiple, es decir, como una forma en construcción, vuelve necesario manifestar los procesos heterogéneos que dan cuenta de su configuración como tal. Para ello, se ha de tener 
presente que la subjetividad se advierte como el proceso mediante el cual el sujeto logra conformarse a sí mismo a partir de una cultura material dada ${ }^{2}$. Desde esta perspectiva, resulta necesario considerar que la escritora ha trabajado constantemente su obra desde el desborde del concepto sujeto, apostando por situarse en y desde los diversos conglomerados que constituyen un cierto tipo de subjetividad "marginal" para, desde allí, apuntar críticamente a las distintas esferas que aportan a su producción. Razón por la que Diamela Eltit se ha abocado provocadoramente a la tarea de profundizar en el cuestionamiento de los "límites" que responden a la construcción cultural de un aparato social normalizador y legitimador de operaciones sociales que surgen y se actualizan para favorecer economías y mercados. Es decir, promoviendo e instaurando una "sociedad "aclarada" a la manera de una súper oferta que construye una trasparencia intemporal, desligada, única, que vislumbra en el conflicto de la interrogación la amenaza de una plaga medieval aniquiladora de la felicidad tecnologizada de lo irreflexivo" (Emergencias 61).

Sin renunciar a la literatura, o más bien desde su resistente saber literario, Diamela Eltit problematiza los límites normalizadores que subyacen de los discursos estéticos, políticos y sociales; toda vez que éstos demuestran su constante "incerteza" - término que utiliza la escritora para referirse a los diversos acomodos y desarreglos que utilizan las economías con la finalidad de poner en juego, modificar o alterar aquellos límites y su normalización- pues, para Eltit la problemática radica en aquellos vectores fluctuantes que de acuerdo a su vínculo mediático con el fluir del capitalismo logran la paradigmática sujeción de carácter homogeneizante y desigual entre los sujetos que se proyectan en el anonimato seriado del acatamiento y los “casos” que ejemplifican las caídas a la norma, cuyo abismo siempre es amenazador y extremo (Emergencias 60).

${ }^{2}$ En este sentido, se destaca el concepto de subjetividad desde la perspectiva del filósofo Gilles Deleuze, considerando el diálogo permanente que éste tiene con la filosofía de Michel Foucault; Deleuze explica la subjetividad como un proceso de interacciones, practicas, movimiento y trascendencia. En sus palabras: "el sujeto se define por un movimiento y como un movimiento, movimiento de desarrollarse a sí mismo. Lo que se desarrolla es sujeto. Ese es el único contenido que se le puede dar a la idea de subjetividad: la mediación, la trascendencia" (91) 
CATEDRAL TomAda: Revista de crítica literaria latinoamericana / Journal of Latin American Literary Criticism

La producción de subjetividades marginales en Fuerzas especiales de Diamela Eltit: la emergencia de un enfoque guattariano

Ahora bien, considerando los intereses de la escritora, es posible mencionar que los casos que ejemplifican las caídas a la norma no sólo se caracterizan por ser el punto más conflictivo de dicha problemática, sino que también, forman el eje central de la obra artística y literaria de Diamela Eltit: a saber, el desborde de la norma y su proyección extrema o amenazante que subyace de la sujeción social de los espacios periféricos y marginales, donde la "incerteza" siempre tiene un punto de encuentro con el abuso de poder, el neoliberalismo, y los múltiples mercados que nacen en y desde el capitalismo. En este sentido, en Fuerzas especiales dicho "abismo del desborde” recae en un espacio “indiferenciado" en el cual, según la autora, "el libre mercado u el consumismo representan una forma de violencia y de destrucción sobre cuerpos y objetos que se verifica en la más desabastecida carencia” (Emergencias 67), junto con la amenaza organizada desde la vigilancia ejercida incesantemente al cuerpo social.

Así pues, la subjetividad entendida como proceso se encontrará mediada por diferentes "máquinas sociales" que intervienen en la elección o adecuación del sujeto a las normas o experiencias de reconocimiento con su entorno. Estas máquinas sociales aparecen/actúan en Fuerzas especiales desde una interesante relación que surge entre la materialidad uniforme y homogénea del bloque (la estructura material que media entre el sujeto y la ciudad) y la inmaterialidad digital de las tecnologías:

Pienso ahora, en este día especial que mantiene mi ánimo relajado y lúcido, que podríamos sobrevivir porque mi madre, mi hermana y yo tenemos un tipo humano tan común que no somos recordadas por nadie. Pero eso me permite asegurar que mi tipo común es en realidad excepcional por el conjunto de beneficios que porta. Soy multitudinaria, soy en todas partes, me proyecto como Dios y me amplifico dotada de una esquirla de divinidad. Pero no soy yo, somos el yo bloque que habita genéticamente en cada uno de nosotros. (78) 
La identificación del sujeto con la estructura homogénea del bloque permite comprender cómo el imaginario urbano-distópico que ficciona Diamela Eltit se presenta como una forma de exterioridad que se relaciona directamente con la interioridad de los sujetos. La uniformidad del bloque, la iteración de un modelo de habitación homogéneo y precario, imagen de los nuevos guetos verticales, se extrapola en los cuerpos que intentan sobrevivir en este espacio de confinación, constituyéndose como una estrategia de resistencia político-vital utilizada por los propios sujetos para protegerse del asedio policial mediante el camuflaje con el territorio. El "yo bloque", según se ha citado, se percibe en los sujetos marginales como una condición corporal hereditaria, que les excluye al mismo tiempo que les identifica. La homogeneidad de este cuerpo se mezcla con la homogeneidad del espacio urbano en el que habitan y en el que se constituyen como un grupo social determinado. El "tipo común", entonces, con el que se identifica la narradora, quiebra todo atisbo de individualidad del sujeto, para proyectarse en una subjetividad de grupo (o clase si se quiere), cuyo eje dinámico se sustenta en la homogeneidad del cuerpo bloque.

De este mismo modo, el cuerpo del sujeto y el cuerpo del bloque logran compenetrarse en la medida en que ambos cuerpos son constantemente vulnerados y vulnerables a la violencia armada de los militares. En este sentido, el bloque se expresa como el repositorio en el que los sujetos marginales materializan su marginalidad, manteniéndose aislados en el ostracismo de las cuatro paredes que sostienen y delimitan los departamentos. Este espacio, al estar dentro del perímetro "problemático" a los ojos del Estado, se convierte en un potencial foco de sospecha, por lo que puede (o merece) ser usurpado. En la posibilidad de este ejercicio de allanamiento radica el máximo terror que azota y violenta a los sujetos que habitan el bloque, ya que este se presenta como el único y precario lugar en el que el sujeto logra resguardarse:

Si se viene abajo el bloque nos convertiremos en cucarachas debajo de nuestros propios caparazones. Porque después del bloque no hay nada, 
CATEDRAL TomAdA: Revista de crítica literaria latinoamericana / Journal of Latin American Literary Criticism

La producción de subjetividades marginales en Fuerzas especiales de Diamela Eltit: la emergencia de un enfoque guattariano

nada más que la policía llevándonos en sus cucas con un ir y venir monótono que ya consume toda nuestra vida. O los autos de los tiras con sus balizas que nos impregnan los oídos y nos obligan a comportarnos como distorsionados juguetes tecnológicos. Así, balizando, nos hemos transformados en sonidos desmedidos que chillan ante una inminente detención. (47)

Así, de este modo, la manifiesta identidad de bloque y sujeto se muestra en la codependencia de uno y otro: el sujeto es el bloque y el bloque es el sujeto. No solamente se implican mutuamente y se co-determinan como el animal y su hábitat, sino que su propia identidad reciproca es producida por la fuerza que engendra el miedo y la vulnerabilidad. El bloque es potencialmente un cuerpo dispuesto para ser allanado, como también lo son los propios cuerpos de los sujetos que lo habitan. Más aún, se podría decir que dicha simetría entre el cuerpo marginal y la estructura suburbana del bloque es producida por la violencia inminente del control y la vigilancia de la fuerza policial pública, tal como lo manifiesta la narradora anónima:

La potencia de los ladridos de los perros me despiertan con un miedo terrible a que entren los ratis o los pacos al cíber y me metan a la cuca [...] que me manoseen, que me violen, que me maten adentro de la cuca o me mutilen en el interior de una tanqueta y me boten a la basura o me dejen tirada, convertida en una buena para nada en una de las calles de los bloques y que si sobrevivo ya no sepa reconocer el camino, la escalera, las grietas, la puerta del departamento. (53)

En este contexto, se comprende que la subjetividad de los sujetos marginales responda directamente a su producción en la semiótica de una ciudad dividida, compartimentada en clases sociales, y dependiente, para la gestación de su orden, de unos márgenes violentamente sitiados; márgenes que le inscriben y le determinan, pues, el sujeto en su marginalidad comprende que su cuerpo, en tanto 
entidad material similar al de los bloques, puede ser en todo momento vulnerado, usurpado y violentado.

\section{CMI: la producción de subjetividades y la respuesta autopoietica}

En Fuerzas especiales la producción de subjetividades marginales recae en un espacio "indiferenciado" altamente vulnerable, en el cual "el libre mercado u el consumismo representan una forma de violencia y de destrucción sobre cuerpos y objetos que se verifica en la más desabastecida carencia” (Emergencias 67). El espacio "indiferenciado" de la periferia que señala la obra de Diamela Eltit responde a la experiencia alienada que nos ofrece, según el filósofo y psicoanalista francés Félix Guattari, el complejo ensamblaje que constituye el "Capitalismo Mundial Integrado" (CMI), concepto que utiliza Guattari para esclarecer el entramado orden del capitalismo contemporáneo. Para resumir algunos puntos, es posible indicar que el CMI se caracteriza por la capacidad de "capitalizar" subjetividades, producirlas y disciplinarlas de acuerdo con un viejo (pero actual) orden social en el que se reproducen y se actualizan jerarquías hegemónicas heredadas de antaño. En este sentido, el CMI es una instancia de poder que no se ejerce en el plano de lo visible, sino que más bien, en el plano de la subjetividad, desplazando su acción hacia una constante producción de lo social, sus modos de producción y el control sobre aquella producción, agudizando de este modo, una constante tensión paroxística entre ricos y pobres.

En El devenir de la subjetividad ${ }^{3}$ Guattari analiza la problemática del CMI y su relación con la subjetividad desde dos ejes que, según su parecer, son fundamentales para explicar la producción de subjetividades capitalísticas. En primer lugar, aborda el eje de los diseños colectivos para explicar cómo los aspectos

${ }^{3}$ Libro que reúne las conferencias, entrevistas y diálogos que realizó Félix Guattari en Chile en el año 1991. La visita fue organizada por Francisco Zegers, Miguel Denis Norambuena y la Embajada de Francia en Chile. 
CATEDRAL TomAda: Revista de crítica literaria latinoamericana / Journal of Latin American Literary Criticism

La producción de subjetividades marginales en Fuerzas especiales de Diamela Eltit: la emergencia de un enfoque guattariano

funcionales de las actividades propias del Estado, cuya finalidad busca proporcionar condiciones aceptables para la vida, logran producir y remodelar la subjetividad tanto individual como social; toda vez que dichos diseños colectivos intervienen en las relaciones de intercambio social y, por ende, en la producción de los territorios existenciales. En segundo lugar, Guattari alude a los medios de comunicación de masas considerando su alta modelización perceptiva que empuja y posibilita la constante mutación de la subjetividad, pues más allá de las representaciones narrativas o informativas, los medios de comunicación de masas logran producir subjetividad (31-33).

Según Guattari, "en la actualidad, el objeto del CMI es un conjunto inseparable: productivo-económico-subjetivo" (Caosmosis 43), razón por la cual es importante cartografiar la polivocidad de la subjetividad en vistas de visibilizar sus interacciones $\mathrm{y}$, desde allí, las diferentes conformaciones de subjetivación (Caosmosis 23) que permitan mapear la relación que se gesta entre el capitalismo y la producción de sociabilidad contemporánea. Cartografía que, efectivamente, traza Diamela Eltit explorando en los dos ejes que tan lucidamente explica Félix Guattari en Chile. Tal como ya se ha mencionado, en Fuerzas especiales la periferia signada por la marginalidad de la urbe produce y delimita un cierto tipo de subjetividad social marcada por el ejercicio de la violencia, la vigilancia y el perímetro cercado. En este territorio el ejercicio de la violencia es perpetrado tanto por el Estado como por los grupos delictuales que allí conviven, instaurando la potencialidad de un espacio abierto a la incertidumbre, la desprotección y el miedo:

La potencia de los ladridos de los perros me despierta con un miedo terrible a que entren lo ratis o los pacos [...] que me manoseen, que me violen, que me maten adentro de la cuca o que me mutilen al interior de una tranqueta y me boten a la basura o me dejen tirada, convertida en una buena para nada en una de las calles de los bloques. (53) 
Esta situación de miedo y vulnerabilidad se vincula, a su vez, con la inmersión masiva de los medios de comunicación en dichos territorios, que particularmente se presentan en la novela como un escape virtual o un aturdimiento anti-reflexivo para quienes habitan en la periferia. Así pues, la panorámica de subjetivación pareciera doble. Por una parte, se presentan los bloques, mientras que, por otra parte, se presenta "el cíber": espacio igualmente cerrado que hace posible accesos para un grupo que tradicionalmente no cuenta con tecnologías o que por lo menos no cuenta con un nivel de conexión a Internet de alto estándar. Espacio de flujo, espacio transversal de consumo y de intercambio sexual. Un espacio de flotación donde la narradora encuentra su trabajo, su escape, su lugar: "tengo que olvidarme del bloque, de los niños, de los dientes, de los cascos. Tengo que olvidarme de mí misma para entregarme en cuerpo y alma a la transparencia que irradia la pantalla" (39). De la relación de ambos ejes entre la compartimentación homogeneizante del espacio urbano-periférico y la tecnologización consumista y de consumo del "ciber-café" es posible dilucidar cómo estas dimensiones maquínicas de subjetivación permiten consolidar la producción de una subjetividad capitalística alienante o marginal.

Aún dentro de los márgenes de la ciudad la digitalización de la red acontece con fuerza. Los celulares y los computadores del "ciber" son las únicas plataformas de comunicación que surgen entre los sujetos alienados y el mundo exterior. Para los habitantes de los bloques "no vale la pena vivir sin las antenas" (123), estas cumplen la función de expandir los límites que configuran el espacio cercado de la periferia. Sin acceso a la red hay pánico y desesperación: “todos los habitantes de los bloques hemos caído en un estado de estupor ante la crisis de los celulares. La ausencia de las llamadas que nos alegraban la vida con su diversidad de estilos, ahora nos empujan a un silencio anormal" (124). Las pantallas son para los sujetosbloque la posibilidad de una multiplicidad, posibilitan el encuentro entre las más diversas temáticas y, desde allí, se presentan como la única escapatoria lúdica y placentera (no por eso menos problemática) para los pobladores del margen. 
CATEDRAL TomAdA: Revista de crítica literaria latinoamericana / Journal of Latin American Literary Criticism

La producción de subjetividades marginales en Fuerzas especiales de Diamela Eltit: la emergencia de un enfoque guattariano

Los sujetos internalizan una multiplicidad de cometidos impuestos por el capitalismo cibernético que se diseminan en una serie de tecnologías en las que se reúnen normas, objetos de consumo, dispositivos de poder y afectos. Esta situación se muestra en la novela a partir del vínculo que se establece, por ejemplo, entre el cíber y la narradora: "El cíber es todo para mí, milagroso, gentil. Yo venero la neutralidad de la computadora que me protege hasta de los crujidos de mí misma" (14); entre la música y el Omar: "El Omar es adicto a un tipo de música intensa y desorganizada que no genera impacto en las redes aunque él la considera como la única creación capaz de perforar los espacios" (92); entre la fármaco y el Lucho: "Nos entregó tres pastillas. Las sacó del cajón que tiene de su computadora. El Lucho quería socorrernos y por eso nos regaló los remedios" (100). En efecto, las tecnologías disponibles en la periferia no solo cumplen la función de conectar a los sujetos-bloque, sino que también, los subsume en la mediatización global, es decir, les captura y les subjetiva desde la premisa del bienestar pasajero pero tramposamente necesario.

En este sentido, el proceso de producción de subjetividades es, como explica Guattari, múltiple y polifónico al provenir de un "complejo de instancias individuales, colectivas e institucionales" (Caosmosis 11) que constituyen al sujeto, toda vez que éste las internaliza como parte constitutiva de sí. No obstante, atendiendo a dicha multiplicidad, cabe destacar que Fuerzas especiales no solo realiza un diagnóstico crítico sobre dichas tecnologías, pues estas, en su calidad virtual, figuran como una posibilidad de reapropiación política de los propios sujetos desagregados. Al final, la novela da cuenta de un descentramiento estético que se relaciona con lo que Guattari denomina "caosmosis", donde el caos no es comprendido como el absoluto desorden, la catástrofe o el fin, sino que más bien, una manera de retroalimentar la complejidad y refundarla en el mismo movimiento en que se produce esa abolición caosmótica. Un proceso que permite la condición para cualquier acto de creación, en palabras del francés: 
La caosmosis rebota y rebrota sobre los estados de cosa, los cuerpos y los focos autopoieticos que ella utiliza con carácter de soporte de desterritorialización; ella es caotización relativa a través de la confrontación de estados heterogéneos de complejidad. Estamos aquí frente a un infinito de entidades virtuales infinitamente rico en posibles, infinitamente enriquecible a partir de procesos creadores. (Caosmosis 137)

En efecto, hay una creatividad que surge desde abajo para contestar el individualismo, la discriminación y la segregación urbana, el monolingüismo económico y la devastación ecológica. Estos procesos creadores permiten la resingularización de la subjetividad, es decir, permiten zafar o recrear el fenómeno homogeneizante y unidimensional al que constantemente nos empuja el capitalismo. Esta apuesta que Guattari llama paradigma ético-político se relaciona con la performance escritural que caracteriza a la narrativa de Diamela Eltit y que evidentemente acontece en Fuerzas especiales, pues, la ruptura de la palabra unívoca junto al quiebre del discurso lógico, permite comprender la escritura de Eltit como una constante performance que utiliza la palabra-acción en toda su expresión para reescribir sujetos, cuerpos y espacios invisibilizados del aparente orden social estable y homogéneo. El uso de la palabra-acción, en este registro, busca aprehender los cuerpos textualizados que sobreviven en los márgenes sociales. Busca, también, hacer cuerpos, es decir, producir nuevas categorías de verdad en consideración al cuerpo que queda abandonado o subsumido bajo los pliegues del discurso oficial de identidad, nación y patria.

Desde esta perspectiva, tanto para Guattari como para el Eltit el arte cumple un rol fundamental en la re-creación de territorios y subjetividades. Para la escritora, por ejemplo, resulta fundamental habitar (mediante la escritura) la complejidad de aquellos lugares minoritarios para, desde allí, establecer problemas sobre aquellos lugares, sobre aquella minoría. En efecto, reescribir cuerpos desagregados y re-agregar formas no tradicionales de hacer resistencia política, bajo nuevos códigos, nuevas fisuras, nuevas virtualidades. Situación que en el 
CATEDRAL TomAdA: Revista de crítica literaria latinoamericana / Journal of Latin American Literary Criticism

La producción de subjetividades marginales en Fuerzas especiales de Diamela Eltit: la emergencia de un enfoque guattariano

microcosmos de Fuerzas especiales acontece tras la re-apropiación de las tecnologías que de antaño sólo servían de escape o embrutecimiento, de esta forma las antenas, el celular y el cíber logran cobrar un nuevo sentido virtual, en su conjunto reapropiado apuntan hacia a nuevos modos potenciales de liberación y resistencia política que resultan esclarecedores:

Los bloques están amurallados por la policía. Los niños y los perros vagan como manadas indiferentes a los detalles del asedio. Los ladridos y los gritos de los niños retumban en mis oídos en medio de este súbito calor sofocante $[\ldots]$ Los pacos y los tiras se vienen con todo. Es parte de nuestra vida. Un avión comercial cruza el cielo. El dios de mentira nos dio vuelta la espalda y se subió al avión sin decir una sola palabra acerca de la resurrección y la vida eterna para los cuerpos bloques. Pero entiendo con optimismo demente que tenemos otra oportunidad [...] Habían doscientas mil armas de sensores fusionadas CBU-97. Estamos parapetados en el cíber. Ya nos digitalizamos. Navegamos el cubículo para probar el primer vídeo juego chileno. Un veloz juego de defensa diseñado por el Lucho, musicalizado por el Omar y perfeccionado por mí. Movemos el cursor con maestría. Empieza el juego. Y entonces aparecemos en la pantalla con el título que diseñamos: "Pakos kuliaos". Había cuatro mil millones de proyectiles de artillería teledirigidos de alto rango XM82 Excalibur. (Eltit, Fuerzas Especiales 163-165)

La producción de subjetividad, en su multiplicidad, alude al modo en que los sujetos se apropian de aquellas reglas, normas y dispositivos que parecieran determinarlo pasivamente, para finalmente trastocarlos o desviarlos, asociándoles a nuevas posibilidades de vida. El sujeto, así, se libera sin necesidad de salir o escapar de lo que constituye la sociedad capitalista, tal como lo evidencian las líneas de fuga que trazan los personajes de la novela, dándole otro sentido al espacio alienante del cíber, convirtiéndole en lugar de creación en el que ellos mismos 
pueden resistir. En esta perspectiva, es menester destacar la puesta en juego de las líneas de fuga que trazan los sujetos marginales al desterritorializar su espacio vital, pues ellos se apropian de las tecnologías que les permiten crear un subespacio virtual de resistencia político-vital. Con todo, la propuesta de Diamela Eltit, apunta a una interferencia crítica de las significaciones (o concepciones) totalizantes y reduccionistas de la supuesta pasividad del sujeto periférico. Con respecto a esto se pueden recoger las certeras palabras de Rodrigo Cánovas (2009), quien expresa la importancia de la apuesta narrativa de la escritora chilena: "Será la escritura de Diamela Eltit la que irá dibujando, en las siguientes décadas y hasta hoy, los contornos de una nueva subjetividad que surge del dolor, de una búsqueda laboriosa, y sin contemplaciones de una nueva expresión" (25). En efecto, dicha propuesta permite abrir un espacio en las letras nacionales a un nuevo sujeto periférico: aquel que resiste en el margen y desde el margen, actualizando su potencia vital desde la tecnología, las poblaciones y creatividad.

\section{A modo de conclusión}

La escritura como campo de experimentación en la obra de Diamela Eltit se presenta como uno de los hitos más importantes a la hora de estudiar su narrativa. En este contexto, examinar los detalles de una escritura situada en el acontecimiento, en el presente, en el ahora, permite constatar cómo la configuración discursiva de su obra se multiplica hacia una posibilidad de lectura amplia y plural. En estos parámetros se ha intentado situar su narrativa bajo el concepto de performance escritural, comprendiendo cómo los referentes conceptuales del arte contemporáneo colindan con su propuesta estético-política. Bajo esta perspectiva, en Fuerzas especiales, la performance escritural de Eltit logra dar cuenta de la producción material de las subjetividades marginales, a través de la repetición de enunciados, de la deformación del lenguaje, y del quiebre de la narración lineal y unívoca, comprendiendo o dando a ver cómo esta producción material de 
CATEDRAL Tomada: Revista de crítica literaria latinoamericana / Journal of Latin American Literary Criticism

La producción de subjetividades marginales en Fuerzas especiales de Diamela Eltit: la emergencia de un enfoque guattariano

subjetividades se encuentra ligada al contexto vivencial y a las sublimaciones capitalistas de consumo y tecnología. Pero, en esta línea, es importante destacar que, lejos de seguir la historicidad del sujeto marginal, visible en gran parte de la literatura canónica, donde se presenta a los habitantes de los márgenes como abyectos y carentes de agencia política, Diamela Eltit fisura dicho discurso para reflexionar acerca del sujeto periférico en resistencia, que, como dirá la propia autora, necesita de "fuerzas especiales" para soportar, sobrevivir y luchar cotidianamente contra el abuso y la miseria producida por el Estado y sus (abusivos) aparatos de poder. Para finalizar, cabe destacar que la emergencia de un enfoque guattariano es hoy la urgencia por la reapropiación de lo posible, de la virtualidad, de la tecnología, de este mundo cibernético que nos empuja al consumo, a ser consumidos y consumirnos. La urgencia de la escritura, una escritura sin armazón que la sostenga, un proceso de creatividad permanente, un intento por recrear la subjetividad. Ser, como diría Severo Sarduy, una Juana de Arco electrónica, actual, contingente.

\section{Bibliografía}

Arenas, Francisca. "Fuerzas especiales de Diamela Eltit: signos anclados en el imaginario de una ciudad desfigurada". Antares 9, 17 (2017): 67-79. Impreso.

Barja, Ethel. "Cámara de eco. La narración del cuerpo sufriente en Fuerzas especiales de Diamela Eltit” Ensayo. Cuadernos del Aleph 10 (2018):19. Impreso.

Cánovas, Roberto. "Diamela Eltit, algunos años antes, algunos años después". Rubí Carreño (ed.) Diamela Eltit: redes locales, redes globales, Madrid: Iberoamérica, 2009. Impreso.

Deleuze, Gilles. Empirismo y subjetividad, Barcelona: Gedisa, 2007. Impreso. 
Eltit, Diamela. Lumpérica, Santiago de Chile: Seix Barral, 2012. Impreso. . Fuerzas especiales, Santiago: Seix Barral, 2013. Impreso. . Emergencias. Escritos sobre literatura, arte y política. Santiago de Chile: Seix Barral, 2014. Impreso.

Espinosa, Patricia. "Representaciones de realidad, sujeto femenino, comunidad y resistencia en Fuerzas especiales de Diamela Eltit". Anales de literatura chilena 19. 29 (2018): 69-81.

Fisher-Lichte, Erika. Estética de lo performativo. Madrid: Abada, 2011. Impreso. Foucault, Michel. La ética del cuidado de sí mismo como práctica de la libertad. Estética, Ética y Hermenéutica. Obras esenciales, Vol. III, Barcelona: Paidós, 1999. Impreso.

Guattari, Félix. Caosmosis, Buenos Aires: Manantial, 1996. Impreso. . El devenir de la subjetividad. Santiago de Chile: Dolmen Ediciones, 1998. Impreso.

Hozven, Roberto. "La escritura disidente de Diamela Eltit". Revista de crítica literaria latinoamericana 67 (2008): 309-322.

Lértora, Juan Carlos. Una poética de la literatura menor: la narrativa de Diamela Eltit. Santiago: Cuarto propio, 1993. Impreso.

Lizana, Paola. "El juego del arte narrativo contemporáneo en Fuerzas especiales de Diamela Eltit: realidad develada y espacio lúdico e irónico de resistencia". Alpha 44 (2017): 211-220.

Navarrete, Sandra. "Miedos al margen: representaciones de la violencia y la precariedad en Fuerzas Especiales de Diamela Eltit". Revista Amérique Latine Histoire et Mémoire. Les Cahiers 34 (2017). Web. 31 mayo. 2018.

Olea, Raquel. "El cuerpo mujer: un recorte de lectura en la narrativa de Diamela Eltit" Revista chilena de literatura 42 (1993): 165-171.

Pinto, Daniela. "Mujer-bloque como alegoría identitaria del sujeto femenino en Fuerzas especiales de Diamela Eltit” Revista Isla Flotante 8 (2018). 
CATEDRAL TOMADA: Revista de crítica literaria latinoamericana / Journal of Latin American Literary Criticism

La producción de subjetividades marginales en Fuerzas especiales de Diamela Eltit: la emergencia de un enfoque guattariano

Prado, Marcela. "La obra literaria de Diamela Eltit: testimonios desde la marginalidad”. Nueva Revista del Pacifico 40 (1995): 139-146. Web.

Preciado, B. Paul. "Género y performance” Zehar 54 (2004): 20-27.

Richard, Nelly. "Prólogo". Diamela Eltit. Lumpérica. Santiago de Chile: Seix Barral, 2008.

Salcido, Miroslava. "Filosofía del performance, performatividad de la filosofía" Revista de investigación teatral 11 (2017): 69-85.

Scarabelli, Laura. "Impuesto a la carne de Diamela Eltit. El cuerpo testigo y el contagio de lo común. Kamchatka, revista de análisis cultural 6 (2015): 973-988.

. "Fuerzas especiales de Diamela Eltit: la épica de la vulnerabilidad" Anales de literatura chilena 29 (2018): 163-178.

Solorza, Paola. "Entrevista a Diamela Eltit: una literatura no consensual. Cuerpo, lugares border y resistencia”. Anclajes XX 1 (2016): 79-89.

Valenzuela, Luis. "Performatividad, dispositivos y política. Fuerzas especiales de Diamela Eltit" Literatura y lingüistica 37 (2018): 43-60. 